\title{
Oxidation of HDPE in the Presence of PVC Grafted with Natural Polyphenols (Tannins) as Antioxidant
}

\author{
Hussein A. Shnawa ${ }^{1 *}$, Moayad I. Khaleel1, Faise J. Muhamed ${ }^{2}$ \\ ${ }^{1}$ Polymer Research Center, University of Basrah, Basrah, Iraq \\ ${ }^{2}$ State Company for Petrochemical Industries, Basrah, Iraq \\ Email: *hussanqi@yahoo.com
}

Received 25 April 2015; accepted 26 May 2015; published 29 May 2015

Copyright (C) 2015 by authors and Scientific Research Publishing Inc.

This work is licensed under the Creative Commons Attribution International License (CC BY). http://creativecommons.org/licenses/by/4.0/

(c) (i) Open Access

\begin{abstract}
In the current research study, an attempt is made to modification of polyvinyl chloride (PVC) by grafting with biologically based phenolic resin, namely, tannins. The reaction was carried out at $110^{\circ} \mathrm{C}$ in DMF solution. FTIR spectra show the presence of phenolic hydroxylic groups and other functional groups of tannins into the PVC-tannins derivative. Evaluation of the new PVC derivative as polymeric antioxidant for high density polyethylene (HDPE) was the main purpose of this study. Samples of HDPE containing (0.0, 0.5 and 2.0) \%W/W from PVC-tannins and pure HDPE were exposed to thermal program by differential scanning calorimetry (DSC) by temperature sweep from $100^{\circ} \mathrm{C}$ to $350^{\circ} \mathrm{C}$. DSC scans of the thermal oxidation process of pure HDPE as well as HDPE with PVC derivative show oxidation exothermic stage started at $195^{\circ} \mathrm{C}$ and continues to $285^{\circ} \mathrm{C}$. The samples of polyethylene contain the PVC-tannins show more resistance to oxidation reactions until $215^{\circ} \mathrm{C}$ for HDPE sample stabilized with $0.5 \%$ and $221^{\circ} \mathrm{C}$ for HDPE stabilized with $2.0 \%$. Faster initiation of degradation rate was observed when HDPE contained PVC-tannins. According to the DSC analysis, the PVC derivative can participate in stabilization mechanism of HDPE but at limited performance.
\end{abstract}

\section{Keywords}

HDPE, Tannins, PVC Modification, Polymeric Antioxidant, Thermal Oxidation

\section{Introduction}

The world production and consumption of polymeric materials are increasing exponentially. High density po-

\footnotetext{
${ }^{*}$ Corresponding author.
}

How to cite this paper: Shnawa, H.A., Khaleel, M.I. and Muhamed, F.J. (2015) Oxidation of HDPE in the Presence of PVC Grafted with Natural Polyphenols (Tannins) as Antioxidant. Open Journal of Polymer Chemistry, 5, 9-16. 
lyethylene (HDPE) represents the majority of thermoplastics currently used in industrial and agricultural application such as food packaging materials and in other application fields. One of the limiting factors in the applications of plastics at high temperatures is their tendency not only to become softer but also to thermally oxidation [1] [2]. HDPE is susceptible to thermal oxidation degradation when exposed to heat, oxygen, or UV radiation. Thermal oxidation of polyethylene types is also susceptible to thermal degradation [3] [4].

HDPE can be protected from oxidation reaction by adding antioxidants. These additives are used to keep the polymeric chains and the original molecular structure intact and therefore properties such as strength, stiffness and toughness can be retained over a longer period.

Antioxidants are often small molecules with sites that can react with free radicals and hydroperoxide intermediates that are produced during oxidation reactions [5] [6]. The effectiveness of all types of antioxidants is dependent on some factors such as the number of reactive groups, chemical structure, migration, some physical properties, concentration of antioxidant and environmental factors [4]. In general, the concentration of these additives decreases during long term uses. Many attempts have been made to solve this important problem, one of which is the use of high concentration of antioxidants or by bonding (grafted) it into polymer chains by chemical reactions or by using high molecular weight antioxidants [4] [7]. Long term antioxidants can give protection during extended use. In contrast to processing antioxidants, those stabilizers designed for long term protection are usually large and complex molecules which have less mobility through the polymer and are less volatile and therefore have superior retention. Antioxidants will be effective for a long period if they exist in the polymer as large and bulky particles or if they are chemically bound to polymer chains.

Polyphenolic materials, in the same manner, such as flavonoids and condensed tannins extracted from plant materials (from forestry or viticulture by-products), are available in high quantities, being historically used in the leather tanning and adhesive industries. Condensed tannins, primarily, are polyphenolic oligomers based on flavanyl repeating units with the hydroxylation pattern which provide a potential antioxidant and chemical modification activity. Polyphenolic materials extracted from plant materials are available in high quantities. In plants, these compounds offer a range of protective roles, including astringency, pathogen, and UV inhibition [7] [9].

Tannins have received increasing attentions due to their potent antioxidant properties and to their marked effects in the prevention of various oxidative stresses-associated diseases such as cancer. In the last few years, the identification and development of phenolic compounds or extracts from different plants have become a major area of health and medical related researches [8] [9]. The purpose of this study was to evaluate grafted tannins (natural polyphenolic molecules) into PVC synthesized by another work in our laboratories as antioxidants for polyethylene.

\section{Materials and Methods}

\subsection{Materials}

Polyvinyl Chloride was supplied from State Company for Petrochemical Industries-Basrah, Iraq, with the following properties: K-value: 66 ; density: $1.45 \mathrm{~g} / \mathrm{cm}^{3}$ (min.); volatiles content: $0.5 \% \mathrm{wt}$. (max.).

Tannins are obtained by isolation from the powder of the eucalyptus outer bark by solid-liquid extraction with $2 \% \mathrm{NaOH}$ solution for 24 hours. Solids were separated by filtration and the resulting liquor was dried to yield a brown powder which was considered the tannins extract.

Sodium hydroxide, THF, $\mathrm{H}_{3} \mathrm{PO}_{4}$ and DMF supplied from Fluka Company; acetoneand ethanol from Thomas Baker, India. These reagents and materials were used without further purification.

\subsection{Methods}

\subsubsection{Modifications of PVC with Tannins}

$6 \mathrm{~g} \mathrm{PVC}$ were dissolved in $25 \mathrm{ml}$ of DMF, and $5.5 \mathrm{~g}$ from tannins (as sodium phenoxide salts) in $25 \mathrm{ml}$ DMF were mixed together at $110^{\circ} \mathrm{C}$ with stirrer. The reaction continuous for one hour after that it was stopped, acidification with $10 \% \mathrm{v} / \mathrm{v} \mathrm{H}_{3} \mathrm{PO}_{4}$. The product filtered and precipitated in cold ethanol. The modified polymer was purified using THF.

\subsubsection{Mixing of PVCT with HDPE}

The PVC-grafted-tannin was mixed with HDPE in the ranges $(0,0.5$, and 2.0$) \% \mathrm{w} / \mathrm{w}$. The two components mixed in the percent of acetone as solvent for PVC-tannin. The mixing process carried out by magnetic stirrer continuous for $30 \mathrm{~min}$. 


\subsection{Test Methods}

Fourier Transform Infrared Spectrometer: FTIR type (Shimatzu FTIR-4800S) was used for infrared spectrometry analysis of PVC before and after modification. $0.5 \mathrm{~g}$ from all samples dissolved in THF and casting on glass plate and evaporation the solvent at room temperature. The prepared polymer films were used for FTIR measurements.

Differential Scanning Calorimetric (DSC): The DSC analysis was performed using a Shimadzu apparatus DSC-60 model, Japan. Samples of HDPE with PVC-tannin mixture (8 - 10) $\mathrm{mg}$ were placed in open aluminum pans under air atmosphere and the heating range between $100^{\circ} \mathrm{C}$ up to $350^{\circ} \mathrm{C}$. All DSC scans were at heating rate at $10^{\circ} \mathrm{C} / \mathrm{min}$. The melting and the oxidation temperatures of the samples can be determined.

\section{Results and Discussion}

Tannins are unique and inexpensive natural polyphenolic material with antioxidant activity. They have multiple adjacent polyhydroxy phenyl groups in their chemical structure [10]-[15]. In the FTIR spectrum of tannins (Figure 1), the band which appears at $3420 \mathrm{~cm}^{-1}$ is stretch vibration absorption of $\mathrm{O}-\mathrm{H}$ phenolic groups which are highly available into tannins structures. The band at $1710 \mathrm{~cm}^{-1}$ is stretch vibration absorption of $\mathrm{C}=\mathrm{O}$. This functional group is one of the main chemical groups into hydrolysable tannins, one type of tannins. Moreover, brands at $1620 \mathrm{~cm}^{-1}, 1540 \mathrm{~cm}^{-1}$, and $1450 \mathrm{~cm}^{-1}$ are corresponded to extending vibration of $\mathrm{C}=\mathrm{C}$ in benzene rings [16].

On the other hand, the variation of the chemical functional groups through the grafting of tannins onto PVC were confirmed by FTIR spectrum as shown in Figure 2 for unmodified PVC and Figure 3 for PVC after modification. The most significant changes in each spectra of the grafted PVC were the appearance of the red-shifted at $(1042-1047) \mathrm{cm}^{-1}$ and at $1160 \mathrm{~cm}^{-1}$ absorption bands due to the $\mathrm{C}-\mathrm{O}$ stretching vibration of ethers as well as the peaks at $(3200-3600) \mathrm{cm}^{-1}$ which were the major characteristic peaks of hydroxyl groups of tannins and that peaks at $(1600-1750) \mathrm{cm}^{-1}$ representing $\mathrm{C}=\mathrm{C}$ stretching bands into tannins (Figure 1 and Figure 3) [16].

According to the FTIR analysis and some of scientific papers such as [17]-[19], the suggested chemical structure of PVC-tannin is represented in Figure 4. PVC-tannin structure consists of grafted of tannins randomly on some repeating units of PVC. This reaction was used for synthesis new derivative from PVC contained phe-nolic hydroxyl groups.Therefore, PVC can be chemically modified by tannins and which are appropriate agents to introduce phenolic groups onto the PVC.

Differential scanning calorimetry, DSC is an important tool of thermal analysis in the experimental characterization of the physical and thermal properties of materials. This analysis provides information on the enthalpy of physical and chemical thermal transitions analogous to, $T g$, phase transitions temperatures, degradation temperatures and behavior of materials under thermal conditions. Differential scanning calorimetry (DSC) provides an easy to use, and sensitive means of characterizing the thermal and thermo-oxidative process of polymeric materials as well as the performance of the antioxidants activity [20].

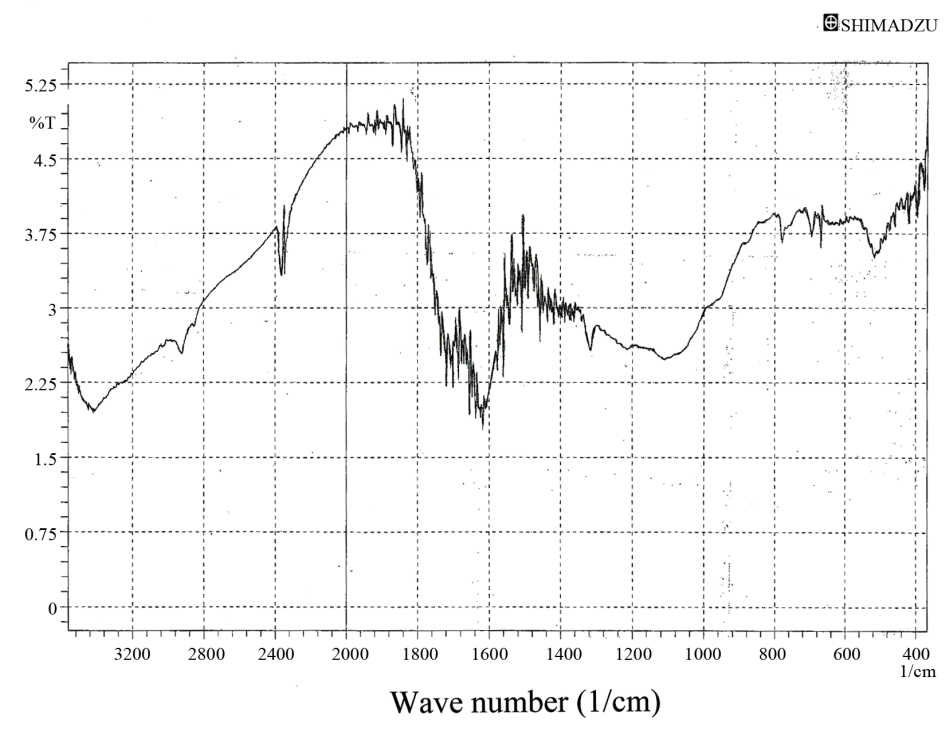

Figure 1. FTIR spectrum of tannins. 


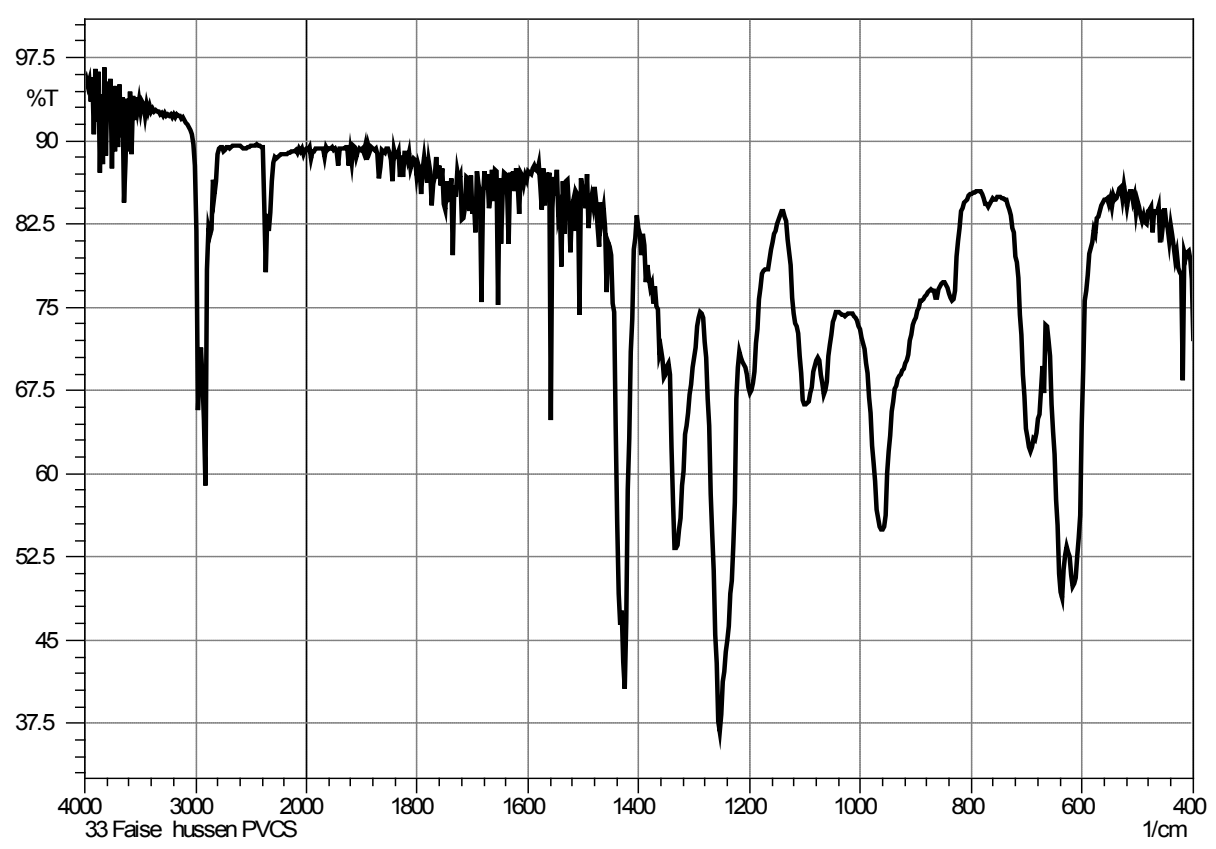

Figure 2. FTIR spectrum of unmodified PVC.

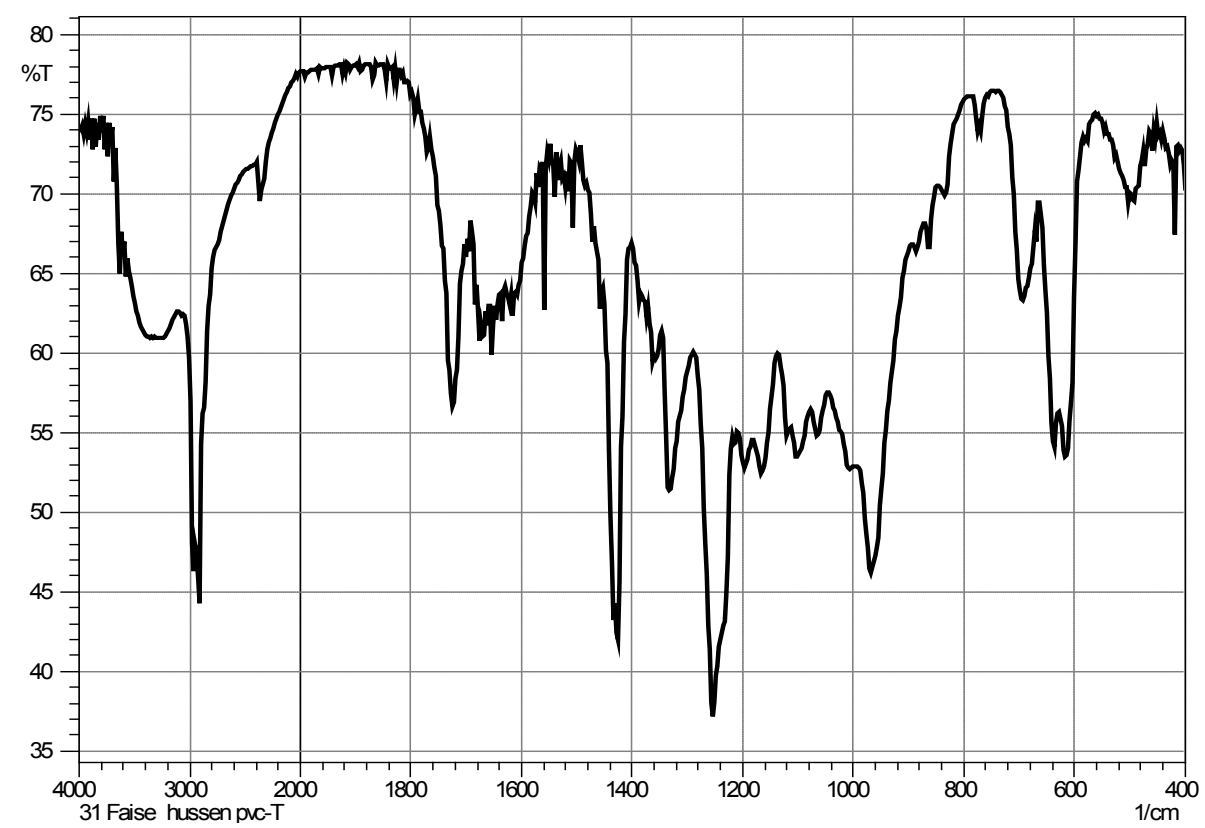

Figure 3. FTIR spectra of modified PVC with tannins.

As can be seen in the DSC scan of pure HDPE (Figure 4), the thermal transition appear as first or second order transitions. One of these transitions is the melting behavior of HDPE, as determined from the peak of the endothermic melting transition in the DSC scan. The thermal transition can be observed at $138^{\circ} \mathrm{C}$. It was recognized that the melting point remains unaltered even after blending with PVC-tannin as appear in Figure $\mathbf{5}$ and Figure 6. The result means that the PVC-tannin doesn't make any noticeable effect on the onset and end-set temperatures of the melting region of HDPE.

The thermal oxidation process of HDPE was determined from the increasing in the heat flow on its thermograms in the DSC scans and this region was used in evolution the activity of PVC-tannin as antioxidant. The 


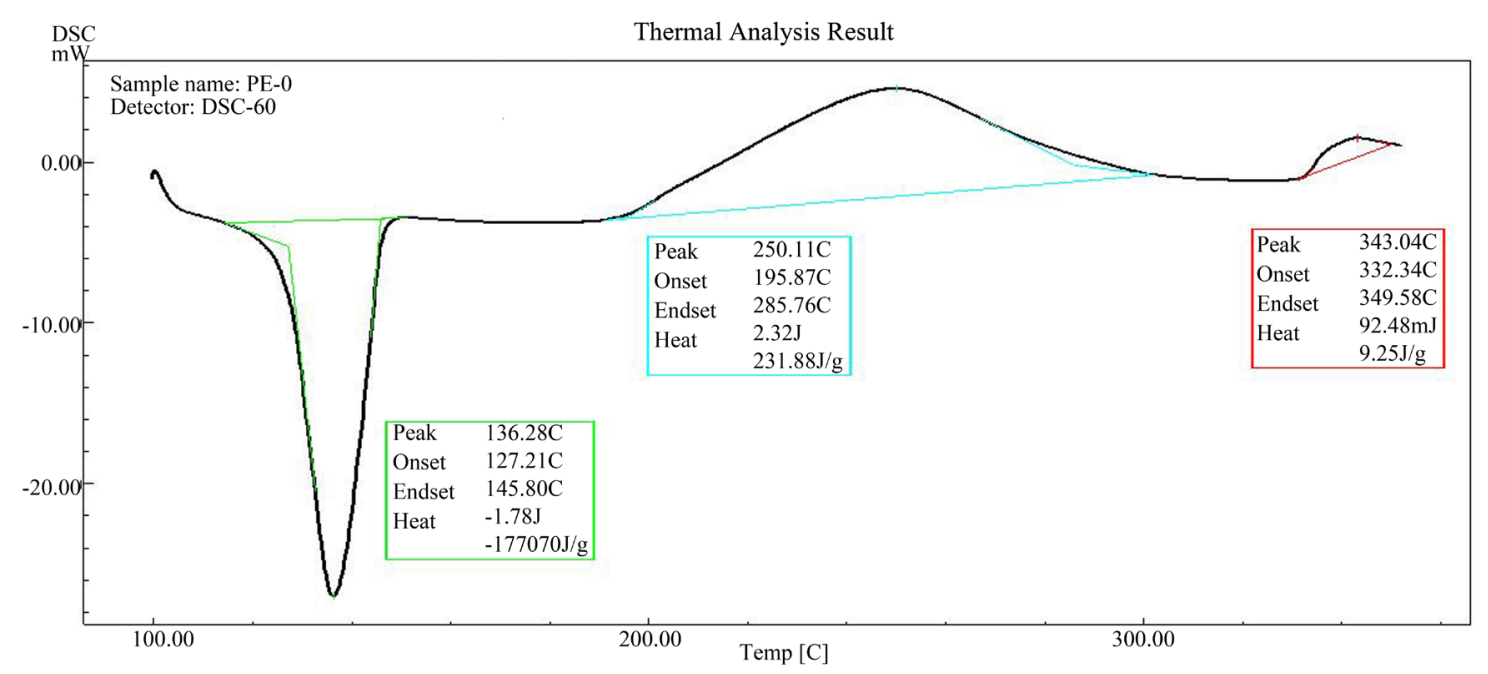

Figure 4. DSC scan of pure HDPE.

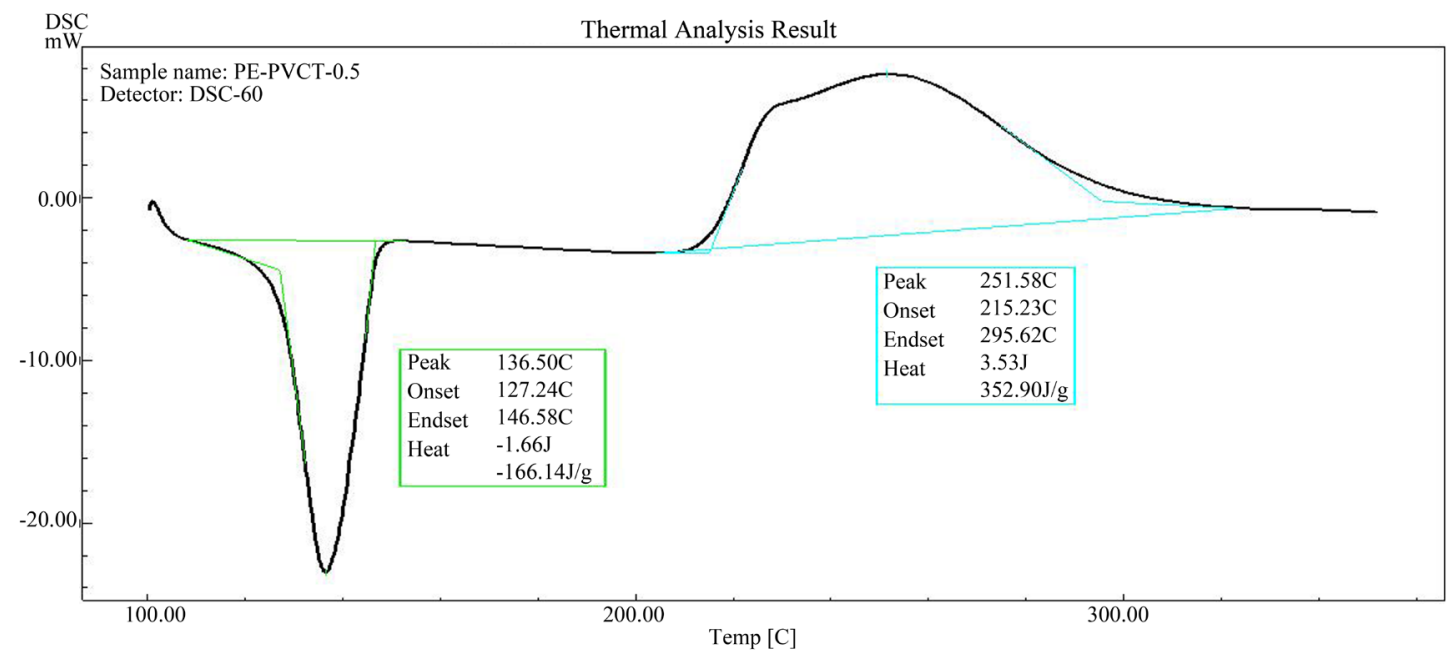

Figure 5. DSC scan of HDPE stabilized with 0.5\% PVC-tannins.

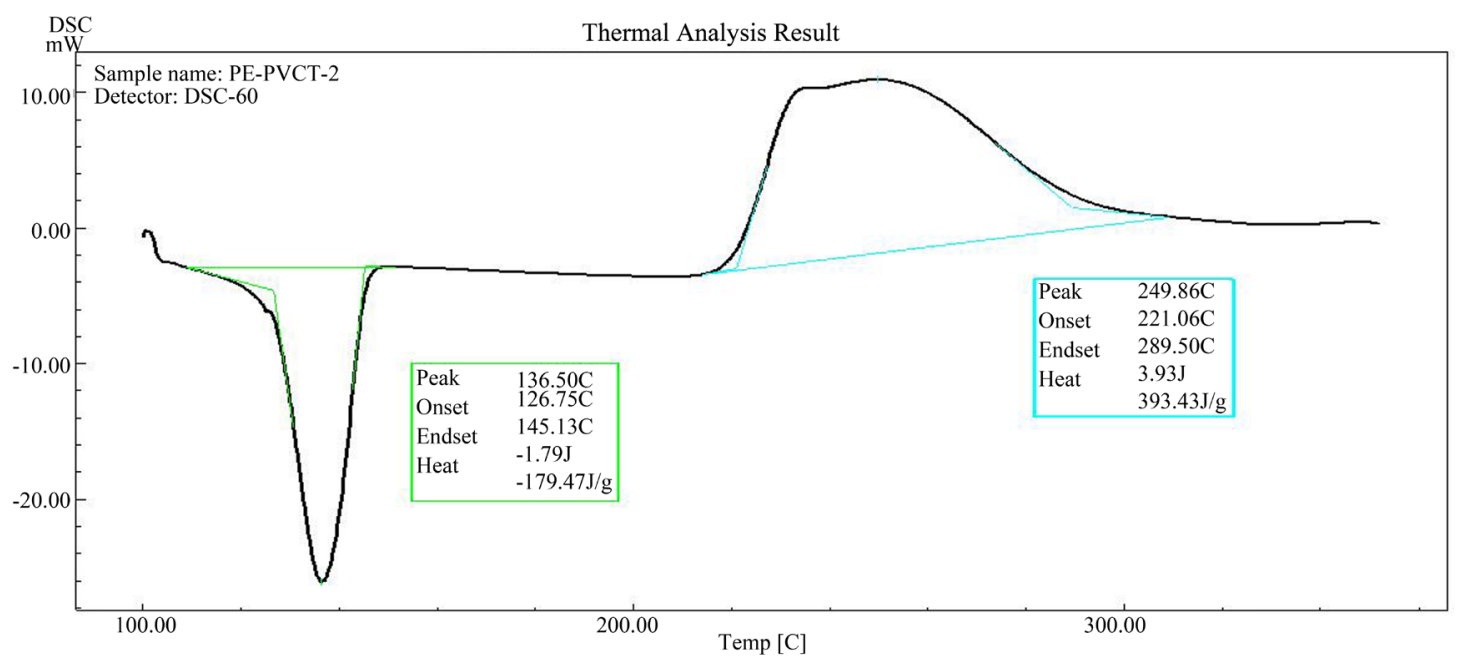

Figure 6. DSC scan of HDPE with 2.0\% PVC-tannins. 
oxidation reaction of HDPE started at $195^{\circ} \mathrm{C}$. The overall shape of this exothermic peak shows a slight increase in the heat flow which continues to $285^{\circ} \mathrm{C}$. And the energy, enthalpy $(\Delta \mathrm{H})$ of this reaction was about $231.88 \mathrm{~J} / \mathrm{g}$, followed by maximum exothermic peak at $343^{\circ} \mathrm{C}$ for thermal degradation of this polymer by causing molecular chain ruptures or scission [21]. It is apparent that the thermal degradation began to occur only after the polymer has absorbed certain amounts of the heat energy.

As can be seen from Figures 4-8, all the samples exhibit single step of oxidation reaction of HDPE with oxygen of atmosphere (air). Also as can be seen from Figure 5 and Figure 6, it was observed that initiation oxidation temperature ( $\left.T_{\text {onset }}\right)$ of oxidation process, which shifts to higher temperatures with presence of PVC-tannins. Where it reach to $215.2^{\circ} \mathrm{C}$ and $221.0^{\circ} \mathrm{C}$ for $0.5 \%$ and $2.0 \%$ PVC-tannin compositions, respectively.

This behavior clearly indicates to that the oxidation reactions of HDPE in the presence of PVC-tannin require relatively longer time periods or higher temperature degrees to occurring. On the other hand, $0.5 \%$ of PVC-tannins reduced the oxidation temperature about $20^{\circ} \mathrm{C}$. The increasing effect in the enthalpy of HDPE oxidation in the presence of this additive Figure $\mathbf{5}$ and Figure $\mathbf{6}$ may come as a result to oxidation process which occurs in

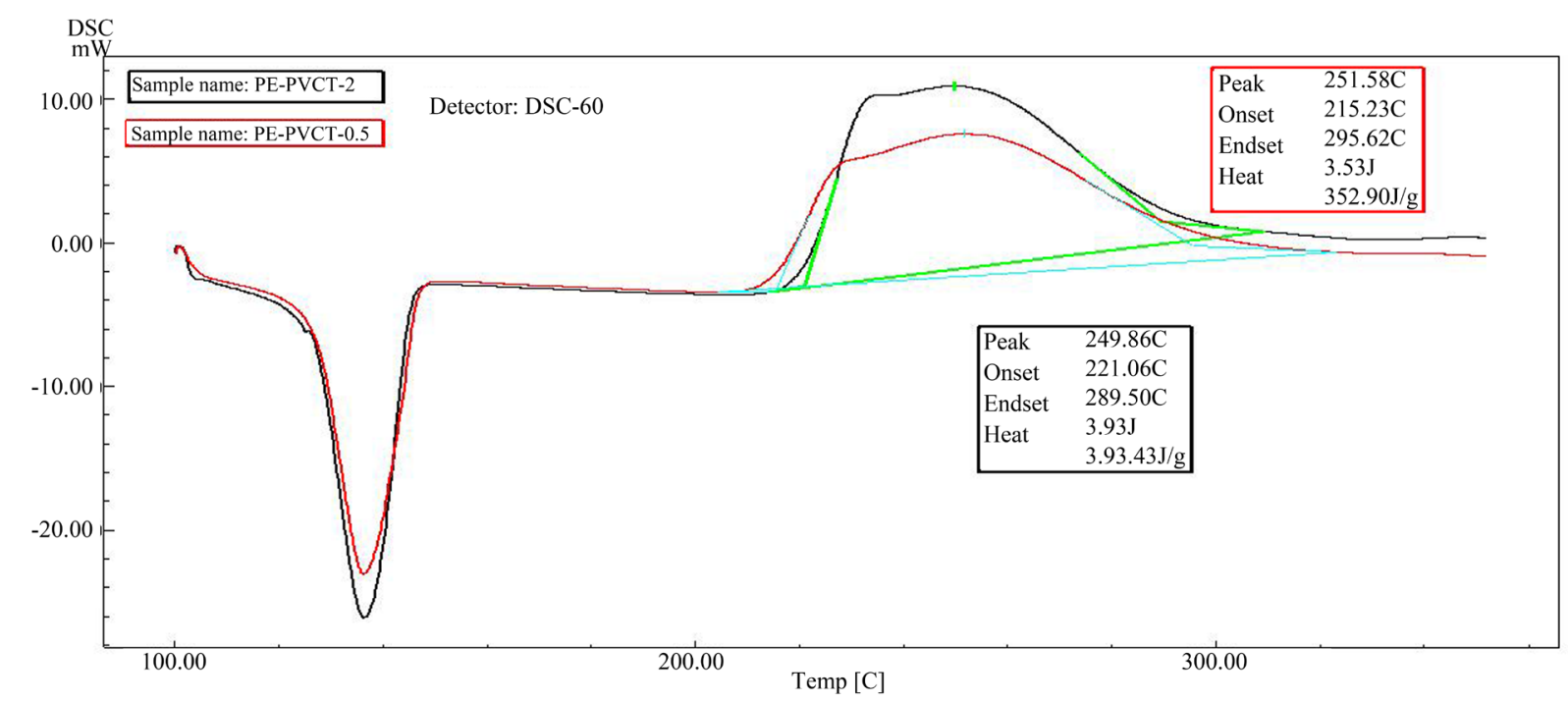

Figure 7. DSC scans of HDPE stabilized with $0.5 \%$ PVC-tannins (red), and of HDPE stabilized with $2.0 \%$ PVC-tannins (black).

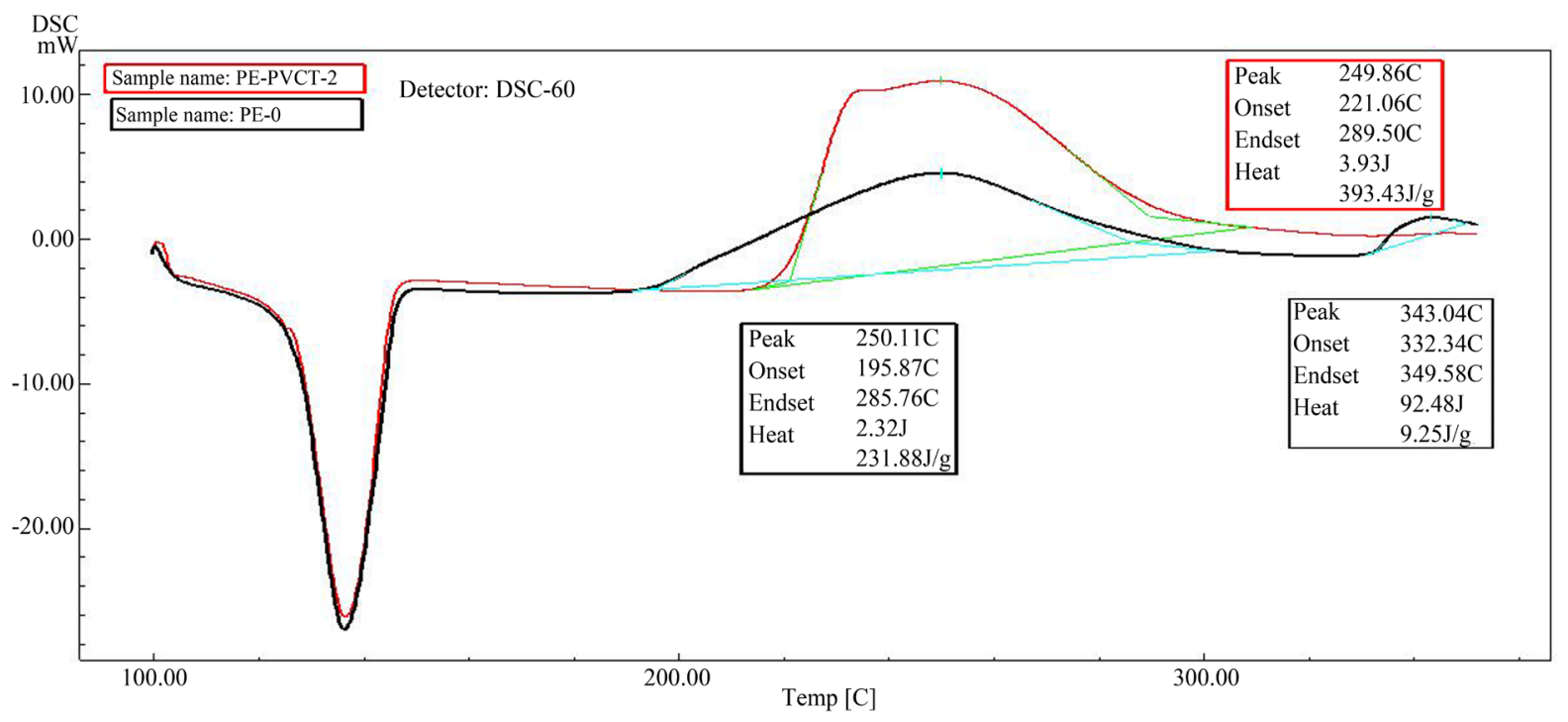

Figure 8. DSC scans of pure HDPE (black), and of HDPE stabilized with 2.0\% PVC-tannins (red). 
higher temperature. Generally, the most of polymeric materials are normally undergoes oxidation degradation reactions under normal use conditions or during exposed to high temperature of molding and extrusion process. Phenolic antioxidants intended to provide protection of the polymers by scavenging or trapping of active free radicals species. The activity of PVC-tannin on oxidation of high density polyethylene may come from the phenolic hydroxyl groups of tannins which are may act as radical scavenger or as proton donors [14] [15]. The combination of tannins into PVC leads to synthesize large bulky particles and non migrating phenolic antioxidant which not be lost either through evaporation or solvent extraction. Therefore, PVC-tannin can act as long term protection agent for HDPE, as can be seen from Figure 5 and Figure 6, PVC-tannin have been shown to be effective at lower temperatures of HDPE oxidation stage and show less activity at higher temperature region.

\section{Conclusion}

DSC analysis and FTIR spectrum refer to that PVC can be chemically modified by reacted it with tannins in basic solution of DMF at $110^{\circ} \mathrm{C}$. This modification leads to appear phenolic hydroxyl groups into PVC with ether linkages. In this research, comparison of DSC scans of pure HDPE with that of HDPE contains PVC-tannins as additive has been studied. Evaluation of PVC-tannins as antioxidant were carried out by using DSC temperature sweep program which show suitable increased in HDPE resistance for oxidation reactions in the presence of PVC-tannins. It can retardant these reactions to higher temperature.

\section{References}

[1] Allen, N.S. and Edge, M. (1992) Fundamentals of Polymer Degradation and Stabilization. 2nd Edition, Elsevier, London.

[2] Mariani, P., Carianni, G. and La Mantia, F.P. (2004) The Antioxidant Effect in Controlling Thermal Degradation of a Low Density Polyethylene Blown Film. Polymer Degradation and Stabilization, 85, 1003-1007.

[3] Grassie, N. and Scott, G. (1985) Polymer Degradation and Stabilization. Cambridge University Press, Cambridge.

[4] Lincoln Hawkins, W. (1984) Polymer Degradation and Stabilization, Vol. 8. In: Polymers/Properties and Applications, Cantow, H.-J., James Harwood, H., Kennedy, J.P., Ledwith, A., Meibner, J., Okamura, S., Henrici-Olive, G. and Olive, S., Eds., Springer Verlag, Berlin.

[5] Al-Malaika, S. (1998) Plastic Additives, an A-Z Reference. Edited by Geoffrey Pritchard, Chapman and Hall, London.

[6] Zweifel, H. (1998) Stabilization of Polymeric Materials. Springer, Berlin.

[7] Brewer, M.S. (2011) Natural Antioxidants: Sources, Compounds, Mechanisms of Action, and Potential Applications. Comprehensive Reviews in Food Science and Food Safety, 10, 221-247.

[8] Elaine, C.R. and Elisabete, F. (2012) Tannin-Phenolic Resins: Synthesis, Characterization, and Application as Matrix in Biobased Composites Reinforced with Sisal Fibers. Composites Part B: Engineering, 43, 2851-2860. http://dx.doi.org/10.1016/j.compositesb.2012.04.049

[9] Laurent, R., Chahinez, A., Eric, D. and Hélène, F. (2013) Depolymerisation of Condensed Tannins in Ethanol as a Gateway to Bio Sourced Phenolic Synthons. Green Chemistry, 15, 3268-3275. http://dx.doi.org/10.1039/c3gc41281d

[10] Grigsby, W.J., Bridson, J.H., Lomas, C. and Elliot, J.-A. (2013) Esterification of Condensed Tannins and Their Impact on the Properties of Poly(lactic acid). Polymers, 5, 344-360. http://dx.doi.org/10.3390/polym5020344

[11] Grigsby, W.J., Bridson, J.H., Lomas, C. and Frey, H. (2014) Evaluating Modified Tannin Esters as Functional Additives in Polypropylene and Biodegradable Aliphatic Polyester. Macromolecular Materials and Engineering, 299, 12511258. http://dx.doi.org/10.1002/mame.201400051

[12] Graciela, P., Juanita, F. and Jaime, B. (2003) Removal of Metal Ions by Modified Pinusradiata Bark and Tannins from Water Solutions. Water Research, 37, 4974-4980. http://dx.doi.org/10.1016/j.watres.2003.08.008

[13] Mahmut, O., Cengiz, S. and Şengil, İ.A. (2006) Studies on Synthesis, Characterization, and Metal Adsorption of Mimosa and Valonia tannin Resins. Journal of Applied Polymer Science, 102, 786-797. http://dx.doi.org/10.1002/app.23944

[14] Wei, S.-D., Zhou, H.-C., Lin, Y.-M., Liao, M.-M. and Chai, W.-M. (2010) MALDI-TOF MS Analysis of Condensed Tannins with Potent Antioxidant Activity from the Leaf, Stem Bark and Root Bark of Acacia confuse. Molecules, 15, 4369-4381. http://dx.doi.org/10.3390/molecules15064369

[15] Formagio, A.S.N., Volobuff, C.R.F., Santiago, M., Cardoso, C.A.L., do Carmo Vieira, M. and Pereira, Z.V. (2014) Evaluation of Antioxidant Activity, Total Flavonoids, Tannins and Phenolic Compounds in Psychotria Leaf Extracts. Antioxidants, 3, 745-757. http://dx.doi.org/10.3390/antiox3040745 
[16] Pantoja-Castroa, M.A. and González-Rodríguez, H. (2011) Study by Infrared Spectroscopy and Thermogravimetric Analysis of Tannins and Tannic Acid. Revista Latinoamericana de Química, 39, 108-112.

[17] Mekki, H. and Belbachir, M. (2007) Preparation of Vinyl Chloride-Vinyl Ether Copolymers via Partial Etherification from PVC. eXPRESS Polymer Letters, 1, 495-498.

[18] Emad, Y., Ayad, H., Adel, K., Yang, F., Noora, A. and Abdualbasit, G. (2009) Synthesis of New Polymers Derived from Poly(vinyl chloride) and Study Their Biological Evaluation. Australian Journal of Basic and Applied Sciences, 3, 1786-1794.

[19] Kameda, T., Ono, M., Grause, G., Mizoguchi, T. and Yoshioka, T. (2009) Chemical Modification of Poly(vinyl chloride) by Nucleophilic Substitution. Polymer Degradation and Stability, 94, 107-112.

[20] Hatakeyama, T. and Quinn, F.X. (1999) Thermal Analysis: Fundamentals and Applications to Polymer Science. John Wiley \& Sons, Ltd., Chichester, New York and UK.

[21] Jeffery, D., Peterson, S., Vyazovkin, C. and Wight, A. (2001) Kinetics of the Thermal and Thermo-Oxidative Degradation of Polystyrene, Polyethylene and Poly(propylene). Macromolecular Chemistry and Physics, 202, 775-784. 